\title{
Astrobiology in Teacher Training. Addressing research method- ology and epistemology in Humanities and social-science classes
}

\author{
Michael Waltemathe ${ }^{1, \star}$ and Elke Hemminger ${ }^{2, \star \star}$ \\ ${ }^{1}$ Visiting Professor, Department of Protestant Theology, University of Duisburg-Essen, Essen, Germany \\ ${ }^{2}$ Professor of Sociology, Department of Sociology, Protestant University of Applied Science, Bochum, Ger- \\ many
}

\begin{abstract}
In a preliminary empirical study of social-science and humanities students enrolled in teacher-training programs at two German universities, the authors have found a disparaging view of technology and science among said students. Their material knowledge of technology and science is the result of content they learned in high-school themselves. After having graduated, they chose social-sciences or humanities as their subjects. There is little or no overlap between science and engineering subjects and social-science and humanities subjects in teacher training programs. Apart from the students choices, this is also the consequence of an institutionally established and strict segregation of the academic fields that does not, unlike in other university systems, require the students to enroll in at least basic interdisciplinary courses. The result for science and technology awareness among the students is problematic, to say the least. While their knowledge of science and technology -being the product of high-school education - is often not up to date and also lacking in current developments, their moral and ethical judgement about the implications of scientific research and use of technology is strong. The preliminary study also showed that the students are interested in new technological and scientific developments, they just lack the ability to include this into their worldview, which is very strongly influenced by their choice of subjects in the humanities and social-sciences. Teaching these students has convinced the authors that their lack of technology and science knowledge combined with their inherent tendency to judge science and technology from the point of view of their respective field, impairs their ability to take an adequate part in science and technology discourse. Their awareness, and thus, their competence to rationally engage with science and technology is lacking. That is in part due to the depiction of science and technology in humanities and social-science courses, and on the other hand due to a lack of current science and technology education as part of a humanities and social-sciences program. The result becomes even more alarming if we assume that the future teachers will continue to relay their heavily biased opinions on science and technology in general, as well as their deficient knowledge of specific technologies to their future students, thus generating a vicious cycle of inadequate technology and science awareness. As the authors' study has shown, these students are really interested in science and technology, they just lack key competencies to make an analytical connec-
\end{abstract}

^e-mail: michael.waltemathe@rub.de

$\star \star$ e-mail: elke.hemminger@evh.de 
tion between their field of choice (humanities and social sciences) and technology and science, without resorting to moral and ethical judgement.

\section{Introduction}

Changing our research focus to a biology that we basically can only speculate about, that we only know about by extrapolating from what we know about our own biology, is a fundamental shift in our research epistemology. By addressing the question of other life in the universe we ask ourselves where our place in the universe is supposed to be. By and large, the social sciences and the humanities have left this field of questions to others; to the engineers and natural scientists, to politicians and sponsoring bodies[3, 16]. However, by staying out of the discussion, the humanities and social sciences shirk their responsibility of analyzing societal tasks and social change on a philosophical or religious level. The fact that this research addresses possible scenarios in the light of current knowledge, but has brought no answer to the original question yet, does not render it any less essential for society, nor should it be an excuse to shy away from academic discourse about this issue. In fact, as astrobiology furthers our understanding of life on Earth as well as life in the universe, the discussion turns from being about purely speculative scenarios into a very immediate possibility, academics from various disciplines are challenged to pave the way for societal discourse by embracing the issues and providing, if not necessarily answers, at least the most urgent questions that should be faced.

In order to achieve this, however, academics from varied disciplines need to engage in shared activities that enhance not only interdisciplinary dialogue, but also cooperative research and teaching projects. Data on academic activities across boundaries of scientific domains are very rare; previous studies have shown that collaboration enhances interdisciplinary research in STEM disciplines (Carayol/Nguyen Thi 2004; Qin et al. 1997). It is a much more challenging task for scholars to cross the boundaries of academic domains such as the humanities or natural sciences. As we currently lack the comprehensive institutional framework for this kind of academic work, any existing initiatives are based mostly on personal interests and commitment rather than structured and officially funded programs[17]. Of course there are numerous exceptions; but, as Metzger et al.[10] state, "the exceptions are just that: limited efforts to introduce real change in a resistant system, one built on the belief that excellence in science meant disciplinary excellence (p.2)." It is, however, essential to state quite clearly that the following argument is not about incorporating scientific issues or concepts and assembling them in a makeshift way into something that seems to be compatible with the social sciences or humanities. In fact, it is the concern of this paper to enhance the exact opposite, a more nuanced understanding of science by the scientifically untrained. After all, excellent interdisciplinary work can only be based on disciplinary expertise. While breaches of the boundary of disciplines can lead to new understanding and radically challenging new discoveries, these breaches can also lead to embarrassing displays of misunderstanding, even deliberate abuse of scientific and academic concepts. The so called 'Sokal Affair' [15] and the problems it addresses is an excellent example of how a lack of understanding leads one area of research to occupy another, use its professional terms in an unacceptable manner and manipulate the findings of another discipline to suit one's own arguments without really having understood the science behind the concepts.[14] ${ }^{1}$ The Sokal Affair resulted from a "prank played by the NYU mathematical physicist Alan Sokal. Late in 1994 he submitted a sham article to the cultural studies journal Social Text, in which he reviewed some current topics in physics and mathematics, and with tongue in cheek drew various cultural, philosophical and political morals

\footnotetext{
${ }^{1}$ An excellent collection of relevant texts to the affair and the problem can be found on Gabriel Stolzenbergs website at Boston University: http://math.bu.edu/people/nk/rr/
} 
that he felt would appeal to fashionable academic commentators on science who question the claims of science to objectivity. The editors of Social Text did not detect that Sokal's article was a hoax, and they published it in the journal's Spring/Summer 1996 issue.1 The hoax was revealed by Sokal in an article for another journal, Lingua Franca;2 he explained that his Social Text article had been 'liberally salted with nonsense,' and in his opinion was accepted only because '(a) it sounded good and (b) it flattered the editors' ideological preconceptions.' [19]

Especially in university teaching the division between the domains of social-sciences and humanities on the one hand and the domain of STEM disciplines on the other hand has serious and long-term effects not only on the way that young academics engage in issues concerning innovative technology, but also on the societal attitude towards them. At a very early stage in their career, in most cases during their last years at school, people have to decide in which area they want to specialize. STEM disciplines are commonly presented as contrasting fields to social-sciences and humanities, supposedly working with completely different methods and asking different questions. Particularly in Germany, university education is extremely specialized from the very start; science students are not meant to take courses in the humanities or social-sciences and vice versa, as it is common in other nations' university systems. Cooperative courses are rare and interdisciplinary dialogue among the students is not notably encouraged. Additionally, previous studies indicate strongly that peer review evaluation systems and the discipline-based reward and career structures discourage interdisciplinary work, especially in young (and non-promoted) academics (e.g. [1, 20]). Thus, the university system is constantly reproducing its current lack of creative and societally relevant research in a "closed epistemological circle" of knowledge production in strict disciplinary structures[5, p.107].

So how can researchers and university teachers meet the societal need for interdisciplinary work without giving up their specialized expert knowledge? How can we face the dilemma of pressing societal questions concerning science and technology on the one hand, and the need for disciplinary expertise on the other hand? In order to address this question, it is necessary to take a closer look at possible reasons for the lack of interdisciplinary work between STEM scientists and academics from the humanities and social sciences. If we consider the history of attempts to cross the boundaries of academic spheres, there are clearly problems, to say the least. Incidents like the Sokal affair show the necessity of a clear and concise understanding of both sides before successfully attempting such research. There are countless other examples of scientists and scholars, experts from one discipline showing their lack of knowledge of another discipline by blindly applying their scientific concepts and academic language to another discipline without true understanding. And just as social scientists and scholars from the humanities help themselves to those scientific concepts that seem somehow useful for their arguments, scientists from STEM subjects in their turn venture into the realms of the humanities and social sciences in order to give their scientific results a more universal meaning. Ultimately, it is only a categorical policy of mutual respect and recognition of the disciplinary expertise of others that can render interdisciplinary work possible in the first place. Both a lack of recognition of the achievements of other academic disciplines and the lack of disciplinary expertise inevitably lead to third-class work at best and eventually contribute to solidify the boundaries between the academic spheres of STEM disciplines and the humanities and social sciences. Yet, there are examples of excellent interdisciplinary work both of individual academics and of several academics working together on cooperative projects. The question is, how do they succeed in producing sound work across the boundaries of disciplines and even academic spheres? Or, in other words, how do those people avoid or overcome the problems discussed above?

In order to find out more about the above questions, the authors of the paper are analyzing academic processes of knowledge production in a comprehensive research project. On the level of research and teaching activities, personal academic networks are analyzed, focusing on possible incentives and barriers for interdisciplinary activities, which can, but not necessarily have to, include 
interdisciplinary collaboration. In addition, university teaching and possibilities for societal outreach are analyzed in two further sub-projects. The results are used for the development of strategies and structural recommendations that enhance communication and cooperation among academics and practitioners from varied disciplines and academic domains and support the establishment of interdisciplinary courses in university teaching, following the hypothesis that measures like this can not only promote interest and expertise in interdisciplinary fields of academic work, but also establish a culture of mutual respect among academics across the disciplines.

In the following, the results of a preliminary survey on the technology and science awareness of students in teacher training programs will be discussed. The paper will then give an introduction to the thought experiment as a teaching method, using astrobiology as an example, and examine its merit as a potential tool in establishing interdisciplinary content in university courses.

While working in teacher training programs the authors of this paper were frequently confronted with problems in their courses when approaching issues that concerned innovative technology and its bearing on society and individual lifestyle. Certain technologies were emotionally evaluated in very strong ways, others were simply not known to most of the students, even though they had recently been discussed in the news. An emotionally detached discussion about possible future scenarios was, in most cases, not possible.

In order to test the authors hypotheses as to the reasons for these problems, a preliminary study was conducted among 100 students in teacher training programs in sociology and theology. Using a standardized questionnaire, the students were asked about their knowledge of certain technological concepts and specific technologies and institutions (only if they knew about them, not what they knew). They were also asked to assess their emotional evaluation of these concepts, institutions and technologies and gave their opinion on the future importance and their personal interest in learning more about these concepts and technologies in their courses. The specific items were selected because they had been in the news during the six weeks preceding the survey. The preliminary study focused on students from the humanities and social-sciences and did not include a control group from other academic domains. As at this moment the study was meant to be explorative and the results are used to build sound hypotheses for the principal study. In the next step of the project, the study will be conducted among students in STEM subjects as well.

The authors' initial hypotheses for the preliminary study assumed that

1. students in humanities and social-sciences have a limited knowledge of innovative technology and science topics;

2. students in humanities and social-sciences have strong emotional connotations for specific technological and scientific concepts;

3. students in humanities and social-sciences ethically evaluate technological and scientific concepts based on the emotional connotations rather than knowledge or an assessment of their possible societal impact.

As the following summary will show, the results partly indicate a confirmation of the above hypotheses, but were, in some cases, surprising. As expected, a high percentage of the surveyed students had knowledge of some general technological concepts, specific technologies and institutions such as GPS $(83 \%)$ or NASA (76\%). In some cases, the numbers were surprisingly low, e.g. the term ,robotics" was known to only 55\% and ESA to merely $38 \%$ of the students. Quite a number of specific institutions and concepts were known to less than 10\%, including Break-Through-Starshot, Human Enhancement, Hyperloop, Mars One and SETI.

On the other hand, the students had very well defined ideas about their emotional connotations. A strong positive connotation was found for roughly $70 \%$ of students concerning information technology 
in general, innovative transportation technology and aerospace technology. As the survey did not collect data on the reasons for this, we can only speculate that the positive connotation might be due to the everyday presence and usage of these technologies (like using a plane to go on holiday or writing messages on a digital device) and a lack of insight into e.g. military aspects of aerospace technology. For the principal study, the reasons of these emotional connotations will have to be addressed. Similarly, the survey showed strongly negative connotations for certain technological concepts, notably nuclear energy, computer implants, brain-computer interfaces and robots in healthcare. This corresponds with the fact that students consider some technologies and concepts to be ethically questionable. Artificial intelligence $(77 \%)$, robotics $(76 \%)$, nuclear technology (74\%) and brain-computer interfaces (70\%) score the highest percentages in this category. As already stated, there are currently no data on the specific reasons for that, but the question will be approached in the principal study. One rather unexpected result was that roughly $40 \%$ of the surveyed students connote the general term 'innovative technology' either neutrally, negatively or strongly negative. If we interpret this as resentment or even fear of innovative technology in general and additionally consider the fact that the surveyed students are going to be future teachers and therefore will influence a whole generation of students on their opinion on technological and scientific innovations, the need for interdisciplinary university courses and societally relevant research across the boundaries of academic domains becomes rather essential. This assumption is supported by another finding of the survey that was unexpected: even though both concepts had appeared in the news previous to the study, more than $45 \%$ of the surveyed students thought of asteroid mining as a science fiction topic; for the concept of Mars colonization the number was even higher with more than $60 \%$ of the students putting it down as a science fiction concept.

In some cases, the data are quite ambiguous, e.g. asked for topics that the students wish to be included in their university courses, high percentages were scored by information technology (49\%), robotics $(39 \%)$ and human enhancement $(57 \%)$. Space exploration ranked last in this question with less than 5\%. On the other hand the students stated that they would like to gain more knowledge about mars colonization (27\%), whereas less than 5\% wish for more knowledge about human enhancement. Where these ambiguities stem from is not clear at this point, but needs to be addressed in the main study. In general, most of the students state that their university education should address innovative technology from a social science $(68 \%)$, educational $(75 \%)$ and ethical $(80 \%)$ perspective. Only less than $5 \%$ of the students are of the opinion that their university courses do address these topics in a sufficient way.

Summing up the results of the preliminary study we can state that the surveyed students from teacher training programs in sociology and theology have some knowledge about specific STEM topics. They are also interested in learning more about some of the concepts, institutions and technologies. The students ethically evaluate STEM topics, even when they are unknown to them and they generally state that ethical and societal questions concerning STEM topics should be part of their university education. However, specific concepts, institutions and technologies are unknown to the greater part of the students. For certain STEM topics, the students stated that they are not interested in learning more about them. And unfortunately the last two areas are identical. Again, we can only speculate on the reasons for this. Hopefully, the lack of interest for the unknown topics is due to hesitation or fear of getting involved in a complex and challenging field of discussion and can therefore be tackled in university education. Apart from the specific reasons, the fact certainly seems to be part of the process that reproduces the gap between academic domains.

In the following part, the paper will now introduce a possible tool that might help to bridge that gap in university teaching, using the example of astrobiology. 


\section{Adding Astrobiology}

This is where the authors believe that the very diverse aspects of the different disciplines relevant to astrobiology will show merits. Astrobiology relies on disciplines from all the STEM fields. The disciplines relevant for astrobiology, like physics, astronomy, engineering, mathematics, chemistry as well as biology and medicine and others consider problems and research questions concerning knowledge about scientific research that also touches on key questions the humanities and social-sciences have been asking for centuries. This interdisciplinary field requires a comprehensive, integrated understanding of biological, astronomical, physical, planetary, and cosmic phenomena to mention a few. Such an understanding is usually outside the scope of high-school education, but could have exemplary character in certain settings to show where, when and how the two supposedly opposing worldviews from the sciences and the humanities overlap.

\section{Changing Worldviews}

Approaching these key questions in an open and scientific way from an interdisciplinary field gives new approaches to the answers the humanities have given, will show some of them to be worthwhile and others to be wrong. It will - in short - change established worldviews. This approaches one of the key problems the authors have identified with their students technology and science awareness. While the students have some understanding of scientific projects or current technology on a practical level, they do not regularly possess sufficient knowledge to adequately understand the workings of the technology or the implications of the scientific results. They have, however, been given information about the sociological und ethical consequences, that they can apply and understand. That means, they approach science and technology with a formed moral and ethical foundation that has only a limited foundation in a deeper understanding in the science behind the technology. Our project aims at approaching these problems. During our survey, most of the students we questioned also stated a high interest to learn more about technology and regret the lack of possibilities in their course of studies in social-sciences and humanities. As a consequence, we suggest using examples of astrobiology as teaching material in humanities and social-science courses.

\section{Teaching with Astrobiology}

Our approach to teaching astrobiology is not so much teaching methods and science of astrobiology in and of itself, but using key concepts of astrobiology research and analysing their underlying assumptions and scientific reasoning. Many of the key concepts of astrobiology are very well suited to show the students how to bridge a perceived conceptual gap between the STEM subjects and their respective fields without having to resort to ethical or even moral evaluation and judgement. For instance the problem of human habitats in space can be an engineering problem concerned with biology, but also point to the bigger philosophical question, what exactly makes a human being human. Without having to resort to ethical and moral questions concerning, for example, environmental protection on planet Earth, the question can be considered from the point of view of astrobiology in a more abstract way. What do we need to take into space with us to keep us not only alive, but fully human?

\section{Thought Experiments}

The common denominator between STEM and humanities and social-sciences while approaching new ground is the thought experiment. The thought experiment has a long history in philosophy, religion 
and other fields of the humanities as well as in the natural sciences. Thought experiments have been used to further the theory of relativity, they have a long history in philosophical schools and they have been widely used in education in the form of ethical dilemmas to enable students to learn to make analytically sound decisions. The basic structure of the thought experiment in either perspective, science and philosophy, relies on hypothetical thinking. The mode of 'what if', that is so vital for scientific progress often gets overlooked in educational settings. The thought experiment forces the learner to employ this attitude to an existing problem without being restricted by preset solutions. In science, the thought experiment is employed when there is no obvious solution or no solution to the given problem at all, or when the problem is in need of a broadening of established theoretical thought. In philosophy the thought experiment is used to demonstrate a school of philosophical thought or to exemplify a philosophical argument. But both ways of using the thought experiment rely on employing an attitude toward the problem that is open for new, surprising ways to learn. It does not convey convictions but rather opens the mind of the student to new experiences and new ways of thinking about established problems. One could argue, that a thought experiment is a mental game with available data. This playful approach is something that humans have always employed when they try to breach the paramount reality of their daily life and have sought new experiences. The thought experiment can be used not to seek new experiences but to seek new knowledge.

\section{Playfulness as the mode of bridging worldviews}

Bridging two (self-constructed) different areas of a students life-world demands a specific way of dealing with these areas in a scholarly and educational context. When we look at, for example, play and game, we find that these have always been the bridge between fantasy and reality. We therefore suggest using a phenomenologically inspired theory of playfulness as the bridge between different provinces of meaning and the paramount reality of the life-world as manifest in what the students so clearly distinguish in their construction of the different spheres of STEM and the humanities and social-sciences. Michael Kolb has shown[8], that play in a phenomenological sense and in the phenomenologically orientated play theories always is the construction of identity defining spheres in our life-world. Play is a flexible, subjectively constructed relationship between human being and world, between inner fantasies and outer reality.

Education by means of playful learning or thought experimentation has to consider how much it wants to rely on controllable educational content and how much room it can give to self exploration and true experimental learning. Walter Vogel argues, that explicit and implicit self-learning are the ways of learning which are immanent in the learning-environment of for example computerworlds[18, pp. 158-172]. The implicit self-learning has several advantages over traditional learning concepts, but some rather disconcerting disadvantages as well. We do not want to discuss those here, but rather state that this type of learning is always implicitly included in playfulness and games and thus cannot be abolished while employing the thought experiment in an educational context. Thought experiments necessarily have an aspect of self-construction and individual learning while hypothetically thinking about possible outcomes of the experiment. The mode in which we conduct the thought experiment, by thinking about the problem within the bounds of the original problem description and then trying to reconcile possible hypothetical solutions with those bounds while trying to think outside of the bounds at the same time can be seen as a stop-and-go motion between established rules and breaking these rules hypothetically. This bipolar mode of access already incorporates the reflective attitude, which is vital for self-learning.

Examples that show the deep connection between scientific methodology from astrobiology examples and current debates in the humanities and social-sciences in an exemplary fashion are for instance the question of the necessary qualities of a habitat for humans in space and the question of 
planetary protection as a consideration for mission design. Both show the deep connection between questions the humanities have been dealing with for a long time and the requirements of mission planning in space exploration, thus arguing for the specific merit that the use of astrobiology in the university classroom has in bridging the perceived divide between STEM and the humanities and social-sciences.

\subsection{Planetary protection and biodiversity}

Finding life on other planets will pose philosophical problems when considering human settlement. Are humans only allowed to settle earthlike planets if there is no indigenous life? Chris McKay and Robert Zubrin have discussed this in relation to the settlement of Mars[9]. While McKay argues from a biocentric stance to change the environment of Mars in such a way as to enable indigenous bacterial life to prosper and enable humans to learn about life itself, Zubrin basically argues to freeze indigenous life and keep it in the lab while making the planet livable for humanity. He employs a strong anthropocentric view of planetary colonization.

Brian Green of the University of Santa Clara - in an opinion piece for CNN[7] - questioned both positions from a philosophical as well as a theological point of view and restructured their discussion to find a middle ground. While this is a valuable ethical debate that needs to be held, there is, however, a more pressing problem that should be addressed concerning anthropocentric and biocentric perspectives when it comes to space-exploration.

This problem is a view of biodiversity - that is different from the standard view - that humans may have to adopt when designing space-missions. While the conservation of biodiversity on planet Earth is at first glance a universally accepted positive value, this may not be the case when it comes to space-exploration. For good reason, space-agencies across the globe try to restrict the number of organisms they carry into space. While this seems a good idea at the current level of space exploration (no human astronaut wants an unintended "fire-ants in space-suits" program), the philosophical and ethical debate about this deliberate screening of biodiversity has not been held when it comes to large scale space missions and can serve as an example for a debate between science and philosophy that enhances students' learning opportunities.

To address the issue of ethical arguments concerning the restriction of biodiversity on spacemissions and an analysis whether human interference in matters of biodiversity on space missions is necessarily restricted to an anthropocentric perspective or how far a biocentric perspective needs to be incorporated into space missions can show students an outside perspective on the ethical debates they are already familiar with. This will show that the same ethical argument may well lead to different solutions in different situations. Thus a distinction between an earth-based biocentrism versus a spacebound biocentric perspective can be made that is clearly differentiated in relation to certain profiles of exploration.

One other necessary ethical argument concerning biodiversity that is beyond just moral condemnation is the discourse about forward contamination within the planetary protection agenda. The problem of possibly introducing earth organisms into other planetary environments is governed by a rule that defines a probability of contamination. The history and scientific genesis of this number can be ethically evaluated and possibly questioned without resorting to a-priori moral condemnation but rather by opening up the dicussion and showing the broad overlap between this technical and scientific question and sociology, ethics, theology, philosophy, policy and law.[13]

Thus the students' approach to science and technology will change from being an ethical or even moral evaluation of these to learning from both sides of the coin and facing the common possibilities of social and scientific growth. 


\section{Furthering Technology awareness}

The authors are currently seeking funding for an electronic teaching tool, that will use the thought experiment in a constructivist pedagogical setting. The tool will provide the students with a) several vetted high quality thought experiments between science, technology and the humanities and also in the field of astrobiology and b) allow the students to construct their own thought experiments. These thought experiments will be represented akin to a text based adventure game with additional audiovisual media. The students can thus on the one hand play with the implications of the thought experiment and gain deeper understanding of (nearly) all possible outcomes and on the other hand construct their own thought experiments to approach and integrate outcomes that have not made their way into the original thought experiment as well as new thought experiments that seem viable to their own learning processes. In this way the students also have to take the role of the teacher while constructing their own thought experiments, a stance that has shown high efficiency in rethinking one's own learning process.

\section{Changed Worldview}

Steven Jay Gould's theory of Non-Overlapping-Magisteria[6] deals with the fundamental gap between science and religion. He proposes that these magisteria can and should not be combined. Religion deals with the "why-questions", Science with the "how-questions". This distinction serves to argue for a worldview that emphasizes the non-overlapping character of these magisteria. The students we tested in the survey seem to have adopted a similar differentiated worldview in which the humanities and social sciences deal with the moral and ethical questions while the sciences are being subjected to these moral questions. While ethical considerations concerning technology are necessary and serve to save society from possibly terrible consequences, they need to be based on a thorough understanding of the technologies and scientific findings evaluated. This is something that we found lacking in our preliminary study. As a consequence we want to emphasize a change in worldview through the abovementioned thought experiments, that includes those seemingly differentiated and non-overlapping-magisteria of the sciences and the humanities. Such a worldview, which is a combination of different scientific and academic traditions is in danger of reducing the complexity of the respective academic perspectives. This is a problem that has to be addressed by thorough understanding of the epistemological and historical traditions of the academic disciplines represented. Of course, this can never be a full understanding but without a certain academic rigour it will fall in the trap of oversimplification and academic usurpation. One example of such an oversimplification is the so called "Intelligent Design" theory, which in an academic understanding is neither. ${ }^{2}$ While we think a worldview that encompasses a bridge between different academic and scientific traditions vital for a modern and complex global society, we also want to emphasize the educational need for new pedagogic approaches like the abovementioned thought experiments within an intertransdisciplinary field like astrobiology to keep such a worldview from falling behind it's possible benefits.

\section{References}

[1] Carayol, N. and Nguyen Thi, T. U., Why Do Academic Scientists Engage in Interdisciplinary Research?, 2004, revised 2005, on: http://ncarayol.u-bordeaux4.fr/interdisciplinarity.pdf (15.08.2017)

\footnotetext{
${ }^{2}$ For an elaborate critique of this endeavor from a biological perspective see[2]
} 
[2] Conway, S. M., Life's Solution. Inevitable Humans in a Lonely Universe, Cambridge University Press, New York, 2003.

[3] Fischer, J., Exzentrische Positionalität im Kosmos. Weltraumfahrt im Blick der modernen Philosophischen Anthropologie, edited by J. Fischer and D. Spreen, Soziologie der Weltraumfahrt, transcript, Bielefeld, 2014, pp. 21-40.

[4] Fischer,J. and Spreen, D., Soziologie der Weltraumfahrt. Zur Einleitung, edited by J. Fischer and D. Spreen, Soziologie der Weltraumfahrt, transcript, Bielefeld, 2014, pp. 7-20.

[5] Frodeman, R., Interdisciplinary research and academic sustainability: managing knowledge in an age of accountability, Environmental Conservation, Vol. 38, No 2, 2011, pp.105-112, on: https://www.researchgate.net/profile/Robert_Frodeman/publication/231884167_Interdisciplinary_research_and_academic_sustainability_Managing_knowledge_in_an_age_of_accountability/links/56efef5908ae52f8ad7f8310.pdf (15.08.2017).

[6] Gould, S. J., Nonoverlapping Magisteria, Natural History 106 (1997), pp 16-22.

[7] Green, Brian P., Is it ethical to colonize Mars?, accessed September 162017 from http://www.cnn.com/2015/10/15/opinions/green-ethics-of-mars-settlement/index.html

[8] Kolb, Michael Spiel als Phänomen - Das Phänomen Spiel. Studien zu phänomenologischanthropologischen Spieltheorien, Sankt Augustin 1990.

[9] McKay, Christopher , Zubrin, Robert, Do Indigenous Martian Bacteria have Precedence over Human Exploration?, accessed September 162017 from http://www.marspapers.org/paper/McKay_2000.pdf.

[10] Metzger, N. and Zare, R. N., Interdisciplinary Research: From Belief to Reality, Science, Vol. 283, no. 5402, 1999, pp. 642 - 643, on: http://igpppublic.ucsd.edu/jorcutt/VO/Metzger_and_Zare.pdf (15.08.2017).

[11] Qin, J., Lancaster, F. W. and Allen, B., Types and Levels of Collaboration in Interdisciplinary Research in the Sciences, Journal of the American Society for Information Science, October 1997, on: https://www.researchgate.net/profile/Jian_Qin3/publication/220433438_Types_and_Levels_of_Collaboration_in_Interdisciplinary_Research_in_the_Sciences/links/54635b830cf2cb7e9da8e5e3.pdf (15.08.2017).

[12] Rammert, W., Technik - Handeln - Wissen. Zu einer pragmatistischen Technik- und Sozialtheorie, 2nd, revised edition, Springer VS, Wiesbaden, 2016.

[13] Sherwood, B, Ponce, A., Waltemathe, M., Forward Contamination of Ocean Worlds: A Stakeholder Conversation, 68th International Astronautical Congress, Adelaide, Australia. Copyright 2017 by Caltech/JPL. Published by the IAF, with permission and released to the IAF to publish in all forms., IAC-17.A1.6.1x40187

[14] Sokal, A., Bricmont, J., Fashionable Nonsense: Postmodern Intellectuals' Abuse of Science, New York: Picador 1998.

[15] Sokal, A. D., Transgressing the Boundaries: Towards a Transformative Hermeneutics of Quantum Gravity", Social Text, 46/47 (1996),pp. 217-252, doi:10.2307/466856, retrieved 30 September 2017

[16] Spreen, D., Weltraum, Körper und Moderne. Eine soziologische Annäherung an den astronautischen Menschen und die Cyborggesellschaft, edited by J. Fischer and D. Spreen, Soziologie der Weltraumfahrt, transcript, Bielefeld, 2014, pp. 41-88.

[17] The Danish Institute for Studies in Research and Research Policy, The design and delivery of inter- and pluri-disciplinary research", Proceedings from MUSCIPOLI Workshop Two, Report from The Danish Institute for Studies in Research and Research Policy 2002/7, 
on: http://ps.au.dk/fileadmin/site_files/filer_forskningsanalyse/dokumenter/afsk/Rapporter/Rapport_2002_7.pdf (15.08.2017)

[18] Vogel, Walter, Religionspädagogik kommunikativ - vernetzt. Möglichkeiten religionspädagogischer Arbeit im Internet, Münster, 2001.

[19] Weinberg, Steven, Sokal's Hoax, The New York Review of Books, Volume XLIII, No. 13, pp 11-15, August 8, 1996, on: http://www.physics.nyu.edu/sokal/weinberg.html, (15.02.2018)

[20] Ziman, J., Prometheus bound: Science in a dynamic steady state, Cambridge, Cambridge University Press, 1994. 